\title{
On the benefits of Philosophy as a Way of Life in a
}

\section{general introductory course}

\author{
Jake Wright, Ph.D.
}

\begin{abstract}
Philosophy as a way of life (PWOL) places investigations of value, meaning, and the good life at the center of philosophical investigation, especially of one's own life. I argue PWOL is compatible with general introductory philosophy courses, further arguing that PWOL-based general introductions have several philosophical and pedagogical benefits. These include the ease with which high impact practices, situated skill development, and students' ability to 'think like a disciplinarian' may be incorporated into such courses, relative to more traditional introductory courses, as well as the demonstration of philosophy's value to students by explicitly tying philosophical investigation to students own lives.
\end{abstract}

\section{Introduction}

Philosophy as a way of life, or PWOL, is, in many important respects, quite different from what Stephen Grimm has called "standard operating procedure" philosophy $(2019,5)$, or SOPP. For example, SOPP often views the discipline as a series of discrete, though often interconnected, problems and subproblems. One may focus professionally on the particulars of causal explanation, material composition, the

\footnotetext{
${ }^{\mathrm{I}}$ DRAFT (Nov. 20I9) accepted for publication in Metaphilosophy.
} 
nature of warrant, and so forth in an effort to arrive at the fact of the matter. By

contrast, PWOL often focuses on broader themes of the good life and how one ought to live one's own life. At the conclusion of PWOL-based classes, students are often able to articulate their own vision of the good life and how they can live in accordance with that view. One way of conceptualizing the difference between SOPP and PWOL courses is that SOPP courses focus on discrete problems or collections of discrete problems as the ultimate goal, PWOL courses use discrete philosophical problems and questions as instrumental tools to motivate personal growth.

As a result of these differences, if one were to reframe one's course from a SOPP- to a PWOL-based course, the resulting course would look and operate quite differently. This is especially true at the introductory level, where general introductory courses seem especially amenable to SOPPorific smorgasbords, with a bit of epistemology here, some philosophy of religion there, and often little effort to connect the units together. In other words, the switch from SOPP to PWOL is not a small lift from an instructional point of view. Further, while there has been increasing discussion regarding how to teach a PWOL-based course, little, if any, scholarship has been developed on the benefits of such a course. Thus, an explicit articulation of these benefits, as well as consideration of potential challenges associated with such courses, seems warranted.

This essay presents such a discussion, focusing especially on general introductory courses. I argue that, compared to SOPPorific general introductions, PWOL-based introductions have at least four benefits. PWOL courses are better positioned to incorporate high impact pedagogical practices, draw on extant literature on first year transitions from high school to college, allow students to more explicitly 
think like a philosopher — that is, engage in successful philosophical practice-and give definitionally novice students a holistic understanding of philosophy's importance both generally and to their own lives.

My discussion proceeds as follows. First, I begin with a discussion of general introduction to philosophy courses and their aims in Section 2. Section 3 briefly sketches what a PWOL-based general introduction might look like. I next discuss the aforementioned benefits of a PWOL-based general introduction in Section 4, followed by consideration of concerns in Section 5. Finally, I present concluding remarks in Section 6.

\section{General introduction to philosophy and its goals}

Perhaps there is no more challenging philosophy course to teach than the general introductory course because of the course's scope and the assumed philosophical abilities of enrolled students. In addition to these challenges, general introductory courses often represent the only formal exposure to academic philosophy that most enrollees will experience; the majority of students in the class will not go on to take another philosophy course. Given these facts, it is worthwhile to begin by reflecting on the aims of our general introductory courses. This section considers implications raised by the scope of general introductory courses, the assumed abilities of students enrolled in such courses, and how we ought to approach the idea of successful general introductory courses.

\section{I. The scope of the general introductory course}


Often, a course's scope is neatly circumscribed by the course title, description, or both. For example, students will have a clear idea of what to expect from courses with titles like Contemporary Moral Issues, History and Philosophy of Science, Intermediate Logic, or Modern Philosophy from Descartes to Kant. By contrast, Introduction to Philosophy establishes no subdisciplinary boundaries which the course may not transgress. One could conceivably include any philosophical topic, provided that topic is presented at a level appropriate for introductory students. As a result, general introductory courses can vary wildly not only from institution to institution, but from instructor to instructor and occasionally from semester to semester.

One side-effect of this potential scope-where the number of potential topics is dramatically constrained by things like the length of the class, instructor comfort, or perceived importance-is that instructors are regularly forced to make editorial judgments vis-à-vis course material. Professor Alpher may include a unit on feminist philosophy that Professor Bethe omits in favor of Confucian philosophy. Dr. Gammow may include neither, instead incorporating a unit on ethics. In each case, Alpher, Bethe, and Gammow presumably have worthwhile and defensible reasons for these decisions. Perhaps Alpher and Bethe omit a unit on ethics via the justification that an introductory ethics course is regularly offered. Perhaps they chose feminist philosophy over Confucian philosophy or vice-versa out of a relative comfort or discomfort with such subfields, or chose to include them out of a commitment to including underrepresented philosophies. Perhaps Gammow included a unit on ethics out of a belief in ethics' importance and in recognition of the relatively low odds that enrolled students will subsequently enroll in Introduction to Ethics. 
In each of the above cases, the sort of editorial judgments applied by Alpher, Bethe, and Gammow to their respective classes is neither unusual or uncontroversial. As philosophy instructors, we might individually disagree with their respective decisions, but it seems difficult to argue that their respective courses cannot constitute a successful general introduction to the discipline per se.

If one must start with all of philosophy and edit one's course down accordingly, one will need to consider how their course is structured. In the case of general introductory courses, a common framework is to structure the course in terms of discrete units based on particular philosophical problems or questions. For example, one might have a unit on epistemology followed by a unit on God's existence, followed by the problem of free will. Because most philosophers are engaged in SOPP in their professional lives, these units are typically presented accordingly as discrete, often unconnected units seeking to answer a particular philosophical question. A unit on God's existence, for example, becomes more narrowly focused on whether there is good evidence for the Abrahamic God's existence, which, in practice, is more narrowly focused on whether students ought to accept or reject a subset of arguments in favor of or in opposition to that God's existence. Once the unit is completed, it is not uncommon for the instructor and the course to move on, never to speak of the unit again or, at best, vaguely waving at some ideas from a previous unit while moving on to the next problem.

The end result in such SOPPorific courses, which constitute the norm among philosophy courses, is that a general introduction to the discipline is often presented as a sampler platter of various discrete philosophical issues that do not form a coherent whole. As I shall argue later, such a presentation limits students' ability to see not only 
how their views in one area influence their views elsewhere, but also how these discrete problems directly impact their lives. It is not difficult for us, as professional philosophers, to understand how one's commitment to physicalism rules out certain options with respect to the concept of a nonphysical God or immaterial soul, but such connections do not seem especially clear to our introductory students.

\subsection{Student skills and background knowledge}

The second key challenge, faced by introductory courses of all types, is the fact that introductory students are definitionally novices with no assumed disciplinary knowledge or skills. This status as novices impacts how the course is taught because such students neither understand the current state of any debate nor possess the ability to successfully engage in the debate (Wright 2019). Thus, much of any general introduction must be dedicated to skills development via basic argumentative analysis (Cashmore 2015), paper writing strategies (Burkard 2017; Cashmore 2015; Turner 2013), metacognitive development (Stokes 20I2) and so on while presenting manageable chunks of limited debate so that students are not overwhelmed. It would be inappropriate, for example, to begin one's semester with the latest issue of Synthese and ask students for their thoughts.

In addition to the significant time that must be devoted to skills development, students' status as definitional novices significantly impacts the degree to which they are capable of truly engaging in what one might call objectively meaningful philosophical investigation. By this, I don't mean to suggest that students' efforts are meaningless; I think that student progress at the introductory level is both vital and meaningful. Instead, I mean something like this: It is unlikely that introductory 
students will be able to settle, once and for all, whether, say, explanations can be distinctively mathematical. In other words, while students leave with a greater understanding of particular issues than they did when they began the course, they will not extend the boundaries of disciplinary knowledge. One simply cannot go from zero to expert in a matter of weeks, and our introductory courses recognize this by the way in which they are structured. This is, in part, why starting with the latest issue of Synthese is inappropriate. Not only do students lack the skills necessary to engage with the articles in that issue, but they also lack an appropriate knowledge of the debate itself to be able to successfully engage at that level.

The end result of this novice status is that what we can reasonably expect from students in a general introductory course will rarely constitute good philosophy. Students will make basic mistakes, fail to anticipate important objections, and present well-worn arguments as somehow novel. They will be unable to engage successfully with particularly technical or cutting edge arguments. However, they will be in a position to make meaningful personal or subjective progress, both in terms of their individual understanding of various philosophical positions and their view of these positions.

\subsection{The successful general introductory philosophy course}

The concerns raised in the preceding subsections naturally prompt the question of what a successful general introduction course does. Clearly, success cannot hinge on successfully introducing all of philosophy. Neither does it seem that a successful general introduction requires coverage of certain core material or views. If this were the case, we would expect some formal set of APA guidelines outlining such standards 
and expectations. For example, in chemistry, the American Chemical Society has engaged in a nearly ten-year project to identify content that arise at varying stages of a chemistry curriculum (T. A. Holme et al. 2018; T. Holme, Luxford, and Murphy 2015; Marek et al. 20I8; Raker, Holme, and Murphy 2013), mapping "Anchoring Concepts and Enduring Understandings [that] are consistent across the undergraduate curriculum" (Raker, Holme, and Murphy 2013, III5). Though this project is not intended to provide a set-in-stone collection of topics that must be covered, even such a rigorous, systematic project to outline common areas of core coverage from course to course has not been undertaken by philosophy.

It seems more plausible, therefore, that the successful general introduction develops particular skills and dispositions. Whether one thinks of these as specific, enumerated outcomes like the list of learning objectives found at the beginning of many syllabi or the development of more abstract goals like "the ability to think philosophically," or a combination of both, the sorts of things we say we want students to actually leave our class with are not content-related. Put differently, what engaged with in a successful general introduction is far less vital than how it is engaged with.

One way of seeing this is to imagine what you would think if one were to meet, ten years after teaching them, a student who enrolled in your class but did not go on to study philosophy as a major or minor. Would you be more disappointed if they were unable to craft Gettier cases or present a coherent version of Jackson's knowledge argument, or would you be more disappointed if they clearly did not take time to think critically or consider important questions? While I can only speak for myself, I imagine that I am not alone in preferring dispositional success compared to contentretention-based success. 


\section{Introduction to Philosophy as a Way of Life}

At this point, it may be helpful to say a bit about how a general introduction course can be reframed as a PWOL-based course. I shall have little novel to say in this section, mostly in deference to excellent PWOL courses that already exist both at the introductory level—for example, Notre Dame’s "God and the Good Life” (“God and the Good Life” 20I9), Suffolk's “Meaning of Life" (Cheraksova 20I4), and the University of California Santa Cruz's “Introduction to Philosophy as a Way of Life” (Donley, Haug, and Rule 20I8) — and at more advanced levels—for example, Wesleyan's "Philosophy as a Way of Life" (Angle 20II), and Yale-NUS's "Philosophy as a Way of Life" (Walker 20I8).

For such courses, a more-or-less standard framework has emerged in which students examine a series of explicitly interconnected topics framed around questions of value, the good life, and how one ought to live. God and the Good Life (2019), for example, asks students to consider four basic questions: How should I decide what to believe? What are my moral obligations? Should I follow a religion? And, what will it take for my life to be meaningful? Throughout PWOL-based courses, students are frequently asked to both engage in traditional philosophical skill development (e.g., close reading and argument reconstruction) while also engaging in explicit reflection on how the course's questions and topics relate to their efforts to live well. At the conclusion of the course, students are commonly assigned a final assessment that asks them to synthesize what they have learned into a coherent, personalized vision of the good life. In short, students are asked to present and defend an account of flourishing, 
as well as how they plan to live in accordance with the values that lead to such flourishing.

At this point, PWOL-based introductory courses may sound like more SOPPorific courses, but with a bit of self-reflection and more explicit links between various sections of the course. All one need do, if this is the case, is take one's SOPP intro and gussy it up with a bit of reflection and brief notes on why one's stance on $p$ might affect their view of $q$. As Grimm noted at the inaugural Philosophy as a Way of Life conference, one could plausibly make a case for any topic's impact on one's conception of the good life. Indeed, one could argue passionately and persuasively, as Grimm did, that our ability to engage in such examination is, by itself, a powerful force that drives human flourishing (Grimm 2019). While this may be true, what distinguishes PWOL-based general introductions is the course's ability to adequately capture these connections at a level that introductory students are able to make between the course, the good live, and their own lives, even with the expert guidance of professional philosophers. It is deeply unclear to introductory students how the nature of disjunction's implications for the justification of Smith's belief that Brown is in Barcelona impacts their conception of the good life. Thus, the sorts of questions included in a PWOL-based general introduction will likely tie into how one conceptualizes the good life-perhaps, in the view of instructors, painfully so.

\section{The Benefits of Introduction to Philosophy as a Way of Life}

My primary goal in this discussion is to articulate the benefits of a PWOL-based general introduction, relative to a SOPP-based introduction. As I argue below, these benefits are both philosophical and pedagogical. Philosophically speaking, PWOL- 
based general introductions give students a vital chance to not only think like philosophers, but live like them. By so doing, PWOL-based introductions represent a particularly powerful defense of philosophy's value to such students via the course's overt focus on philosophy's implications for their own flourishing. Pedagogically, PWOL-based courses present unique opportunities for students to think like a disciplinarian and for instructors to incorporate high impact practices while drawing on pedagogical principles that have been shown to be especially useful for first year students and students in transition.

\section{I. Philosophy as a Way of Life and the defense of philosophy's intrinsic value}

One of the greatest challenges we face when teaching philosophy at the introductory level to novice students, most of whom will not pursue formal philosophical study beyond the current course and are simply present out of a desire to check some box on a list of degree requirements, is explaining philosophy's value both broadly and within students' own lives.

As a professional philosopher, I'm always shocked when nonphilosophers remark to me that their minds don't work in a philosophical way. For example, at my home institution, first year students are given a choice of continuing with a second semester of philosophy or a second semester of sociology. Because my campus is quite small, I often have the chance to discuss students' choices informally with them. By far, the most common response I get from students who showed great skill as novice philosophers is that they enjoyed the class, but their mind "just doesn't work that way." Similarly, when other adults find out I am a philosophy professor, they frequently 
remark that they took a philosophy course in college, but it wasn't for them. Again, their mind "just didn't work that way."

What shocks me about such responses is that such thinking, writ large, is neither different nor hard. As a colleague of mine describes the practice of philosophy to his students, philosophy is, in essence, the act of thinking in slow motion. Such responses are especially distressing when given by my former students; I know their minds work that way because I've experienced their minds working that way first hand!

One possible cause of this disconnect is the nature of the debate itself at the introductory level. Another possible cause is the highly specialized, problematized nature of SOPP. A third possibility is the lack of a clear connection between the practice of philosophy and one's own life. PWOL-based introductory courses address each of these concerns.

\section{I.I. $\quad$ The nature of the debate at the introductory level}

The presupposition that novice students have no background in formal philosophical practice has important implications for how one is able to teach any introductory course. One of the most important implications is that students are not equipped to engage deeply with any philosophical debate in the sense that they lack the skills, background knowledge, and time to get up to speed on the contemporary state of the debate for any philosophical problem over the course of a semester. Thus, in a particular sense, the goal of introductory courses from a content perspective is not to bring students to this point, but rather to familiarize themselves with the broad outlines of a particular debate (Wright 2019). One curious effect of this is that students 
are unlikely to make definitive objective progress with respect to any philosophical problem, but they are in a position to make personal progress in their understanding of various questions and how they relate to their lives.

PWOL-based courses are especially well suited for student progress in this area precisely because PWOL is intrinsically focused on student personal progress. If students are asked to philosophically defend how they should live and have started the course with no formal background in the practice of philosophy, successfully completing the course seems to require that students use the course not as an opportunity to become content masters or expert philosophers, but individuals with a clearer sense of what they value and how they should live in accordance with those values. Put differently, success in a PWOL-based general introduction is predicated on personal progress. They know that they can think like a philosopher because they have done so in response to vital questions related to their own lives.

\section{I.2. The problematized nature of SOPP and the connection between philosophy and} one's own life

Regarding concerns about SOPP's specialized, problematized nature and the lack of connection between SOPP-based topics and the good life, recall Grimm's earlier point that essentially any philosophical problem can be refocused on questions of flourishing and the good life. While this is certainly the case, such connections are not immediately obvious to novice philosophy students (and occasionally practiced professionals). For example, how would a philosophical novice relate the question of distinctively mathematical explanations to their conception of the good life? I might do so by noting that explanations in general have important implications for what we 
can know and how we can predict—and if necessary, intervene in-events. These abilities then rule in or rule out certain beliefs and actions as appropriate, which in turn rule some goals in or out. If explanations cannot be distinctively mathematical, a certain set of beliefs and dispositions is therefore ruled out. But the introductory student does not see this, nor do I think they could be made to see this without a herculean effort on the part of the instructor. Without such effort, many discrete philosophical problems are so much esoterica. The drawback of SOPP-based introductory courses is that either such an effort to connect material with students' lives either is not made or falls flat.

By contrast, PWOL makes the connection between course materials and students' lives explicit by examining material that cannot but help inform students' views of their own lives. By focusing the course on questions like, "Should I practice a religion?" or, "Is my death bad for me?" philosophical questions are explicitly framed not only as a search for truth, but also as an interrogation of how one's justified beliefs impact one's own life.

In my experience, students find topics interesting to the extent that they are able to relate to them. In end-of-semester surveys, my students regularly rate questions about life's meaning and God's existence, as the most interesting and enjoyable units. One advantage of PWOL-based general introductions is that the connection between philosophy and one's everyday life is made explicit. If the course centers on what the individual student ought to value and how the individual student ought to live their life using philosophy as the lens through which such investigation takes place, one would have to actively try to not see the value of philosophy, at least within their own life. 
Such an explicit connection between philosophical practice and students' own lives is more than a motivating pedagogical tool. It is a powerful defense of the value of philosophy per se. My institution is not the only university to require a philosophy course while offering neither a major nor a minor, and even at institutions that grant such degrees, the overwhelming majority of introductory students will not go on to obtain such a degree. Indeed, most will not go on to take a second philosophy course. If one is studying to be a chemist or a consultant, it can be difficult to see why philosophy requirements exist. But by focusing the class on using philosophy to help students sort out important questions in their own lives, often in a way that other disciplines simply cannot, students are able to experience the value of philosophy directly.

\subsection{The pedagogical benefits of Introduction to Philosophy as a Way of Life}

In addition to the purely philosophical benefits of PWOL-based general introductions, there are also a number of pedagogical benefits. Most notably, PWOL-based general introductions are more naturally able to incorporate high impact pedagogical practices, implement skill-building strategies found to be especially effective for first year students, and allow students to think like a disciplinarian (i.e., think and practice like a philosopher).

In most cases, as I shall discuss below, it is not the case that PWOL-based courses are uniquely suited to achieve these benefits. Rather, such courses are more likely or better positioned to achieve these benefits, relative to SOPP-based introductions. Put differently, it is certainly the case that innovative assignments are often content neutral, but that doesn't mean that certain pedagogical choices, like 
teaching a PWOL-based general introduction, can be more or less amenable to such assignments.

\subsection{High impact practices}

High impact practices are teaching and learning practices that have been widely shown to increase student learning for students from a variety of backgrounds (Kuh 2008). While they are often discussed at the curricular level (e.g., learning communities that encourage students to discuss so-called "big questions" in the context of their wider course load), there is no reason in principle that their primary goals cannot be realized at the course level. Though philosophy courses in general are able to integrate high impact practices, PWOL-based general introductions are especially well suited to do so.

For example, the aforementioned learning communities that encourage discussion of big questions can naturally be integrated into PWOL-based introductions. In such communities, students work closely as a group to explore questions whose importance extends beyond the classroom. It is hard to think of such a question with more obvious import than what one should value and how one should live. Further, it's clear that the consideration of such questions benefits from regular discussion, rather than relying solely on solitary meditation. Thus, a natural pedagogical strategy for a PWOL-based course would be to regularly encourage students to work in groups when thinking through these bigger questions.

Similarly, a course that asks students to articulate a view of the good life can also promote diversity by exposing students to a variety of conceptions of the good life as defended by their fellow students. One advantage of teaching the debate within a 
philosophy class is the ability to expose students to views and arguments that they might not share or even fundamentally oppose (Besong 2016). Framing this exploration in the context of students themselves being asked to articulate their view of a fundamental question for which there exists a wide variety of defensible answers enhances this goal by requiring students to not only engage with views that are different from their own, but with individuals who hold such views.

Both the creation of learning communities and strategies amenable to the promotion of diversity speak to the course's ability to incorporate collaborative work into the course. As Kuh notes (2008), there is a great deal of benefit in students listening seriously to their fellow students, especially when those students' experiences are different from one's own, and such collaboration has been a hallmark of publicly available PWOL-based courses. Indeed, the recent Philosophy as a Way of Life conference was a veritable cornucopia of such assignments, with presentations and discussions of debates ("God and the Good Life" 2019), games (Cheraksova 2014), and opportunities to create visual representations of students' views on a particular topic (Christy 2019).

Further, at a minimum, structuring the course so that the final unit is a synthesis of previous units seems to naturally lend itself to collaboration, even if such collaboration does not take place within the bounds of a formal assessment. Asking students to finish the course by constructing their own meaning would make little sense if that construction was largely facilitated via the instructor's lecture. On the other hand, asking students to work through these issues together and respond to each other's ideas seems like a much more natural fit for such a unit. Such collaborative work could easily be extended to reflective assignments scattered throughout the 
middle section of the course, with students discussing and responding to each other's takeaways, questions, and insights.

\subsubsection{Situated skill development}

If the mark of a successful general introductory course is skill-based and dispositional, rather than content-based, it is useful to consider how best to develop the sorts of skills that we want to develop, like critical thinking, argument construction and analysis, and philosophical writing. Research on this issue exists across the scholarship of teaching and learning, but literature from the perspective of first year academic seminar courses, often explicitly aimed solely at skill development, is especially useful because the students in such courses are so likely to be first year students.

This research demonstrates that skill development is most effective when it practiced rather than presented (Zerr and Bjerke 2016) and is contextualized in student construction of meaning on a topic of interest to them (Brent 2005; Kenny et al. 1998), a finding noted throughout teaching and learning scholarship (Abrantes, Seabra, and Lages 2007; Bergin and Reilly 2019; Pintrich and De Groot 1990; Yuretich et al. 200I). As Brent notes, "the road to academic literacy involves pedagogies of integration, extended process, and grounding in genuine inquiry" (2005, 258).

In other words, it is not enough to ask students to simply learn how to, for example, take notes, nor is it enough to simply give students an exercise in which they are asked to take notes using whatever method has been demonstrated. For maximum effectiveness, students must be put in a position where their notetaking skills are a necessary component of their own knowledge construction for a question of interest to them. Thus, developing philosophical skills and dispositions should ideally take place 
within a context of interest to students where student success at applying these skills has a direct bearing on their own knowledge construction. It is again difficult to think of a topic of more interest to students then how they ought to live their own lives, so it is again difficult to think of a philosophical topic which would be better positioned to develop these skills in novice students.

\subsubsection{The ability to think like a disciplinarian}

One of the most frustrating aspects of teaching philosophy, especially at the introductory level, is that it can often be unclear whether students are genuinely engaging in successful—though nascent—disciplinary practice or whether they are merely engaging in what Meyer and Land (2005) call mimicry, simply regurgitating what students believe the instructors want to hear. Such mimicry is common in a variety of disciplines and has been explicitly noted in philosophy (Besong 20I6; Momeyer 1995). While the former represents genuine understanding of critical disciplinary threshold concepts (Meyer and Land 2005), the latter is not indicative of any genuine philosophical learning beyond a student's potential ability to suss out what the instructor is looking for. Put in terms of Bloom's taxonomy, students who think like a disciplinarian are creating, while students engaged in mimicry are often at best evaluating or analyzing. However, at the introductory level especially, the distinction between these two can be difficult to distinguish because students' lack of disciplinary content knowledge can make it difficult for even more gifted students to extend their analysis beyond the sorts of basic moves contained in literature they have read for class. 
For example, suppose introductory students are assigned an essay on abortion, having read and discussed standard introductory-level sources like Thomson's "A defense of abortion," Marquis' "Why abortion is immoral," or Tooley's "Abortion and infanticide." Given students' lack of knowledge with respect to the current state of the debate and their lack of disciplinary background knowledge, the student who genuinely engages in thoughtful philosophical practice and the student who mimics such practice can be difficult to distinguish. Both will likely stick close to the assigned readings and class discussion, make the same sorts of moves, and advance roughly the same arguments. Yet it is only the former that allows for genuine understanding, both of the material itself and of how to engage with the material philosophically.

This ability to think like a disciplinarian has several pedagogical benefits, including motivating students to create their own knowledge and make novel distinctions (Langer 1993), distinguish between the stability of their own internal views and the stability of consensus surrounding the underlying phenomenon (Langer 2000), and encouraging students to creatively and spontaneously apply information they have learned (Langer et al. 1989). By contrast, more traditional pedagogical strategies (e.g., strategies common to SOPP-based courses) can inhibit student learning of critical threshold concepts (Land et al. 2005). In short, thinking like a disciplinarian makes students better able to understand disciplinary threshold concepts-in this case, the sorts of skills we seek to develop in our students.

PWOL-based general introductions are better able to position students to think like disciplinarians. The sorts of questions PWOL-based courses ask often diverge significantly from mere repetition or rearrangement of content knowledge by asking students to synthesize course material and apply it to their own lives. For example, 
some PWOL-based courses ask students to reflect not only on their view of the good life, but also what in their own lives is preventing them from achieving the good life. Students in other courses are asked to live like a member of a particular philosophical school for a week and critically reflect on the experience. Such requirements make it easier for instructors to distinguish between genuine cases of successful practice and mimicry. This encourages genuine philosophical engagement in two ways.

First, if students recognize that successful completion of the course cannot be accomplished (or can be accomplished less well or less reliably) via mimicry, they will be disincentivized to engage in such mimicry and instead be motivated to engage in genuine disciplinary practice, even if their underlying motivation is to earn the grade they think is necessary and move on.

Second, by providing assignments that are better able to distinguish between genuine engagement and mere mimicry, instructors can craft assessment tools like rubrics that more clearly delineate for students what the difference between engagement and mimicry looks like in a successful assignment. In other words, instructors are better positioned to help students see in advance what sorts of submissions will lead to genuine engagement and therefore a better grade.

\section{Concerns about Introduction to Philosophy as a Way of Life}

Though I have argued there are a number of philosophical and pedagogical benefits to a PWOL-based general introductory course, there are also concerns in need of consideration, especially if many of the pedagogical benefits discussed above are not exclusive to PWOL-based courses. It may be worthwhile to design a more SOPPorific 
course, even if the pedagogical benefits are less fully realized or require greater effort to realize, if the drawbacks of PWOL-based courses are significant enough.

In this section, I address two potential concerns with PWOL-based general introductions: the concern that PWOL-based courses are ultimately ethics courses and the need for traditional philosophical training within a philosophy class.

\section{I. Philosophy as a Way of Life is ultimately an ethics course, not a general introduction}

As described above, one may reasonably conclude that a course focused on concepts of the good life and how to live in accordance with one's values may be an appropriate introductory course, but it is more clearly Introduction to Ethics than Introduction to Philosophy. There are, I think, two responses to such an objection.

In the first case, let us grant the objection. At a certain level, it is difficult to see what rides on its truth. Introduction to Ethics is a common introductory philosophy course at nearly every institution and is often as or nearly as popular when compared to general introductory courses. If a particular instructor feels that the course structure outlined here would be better suited for an ethics course, then such a course could be straightforwardly designed and largely retain the benefits discussed above.

However, my view is that the proposed course structure will function better as a general introduction because the sorts of questions one must answer to articulate a vision of the good life extend beyond ethics. Thus, relying on an Introduction to Ethics course, rather than an Introduction to Philosophy course, as the lens through which students interrogate questions of meaning and value in their own lives will likely leave some important feature out simply on the grounds that consideration of that feature does not constitute ethics. 
For example, suppose one wishes to consider whether the good life is one in strict obedience to God's commands. Such a view is often considered within introductory ethics courses—at least as a normative ethical theory—and the pros and cons of such a view are discussed. What is typically left behind in ethical discussions of divine command theory, however, is whether we have good reason to suppose that God exists. This is typically because such a question is metaphysical, rather than ethical, in nature; it is assumed out of necessity that students at least have a view on the matter and ideally have a defensible argument in favor of that view. But because the course is an introductory one, such an assumption is largely inappropriate even if necessary. Introductory courses, by their nature, presuppose no formal background in a particular discipline, which means that, absent some good reason to believe to the contrary, like an Intro prerequisite where the instructor knows that philosophy of religion has been discussed, we ought not assume that students have thought systematically about such topics.

This inability to assume that students have made no philosophical investigation of, in this case, God's existence, can have profound effects on students' views of the good life and how it ought to be lived. After all, if there is no God, one probably ought not live according to God's commands. Yet an ethics course is not really in a position to engage in a sustained interrogation of arguments for and against God's existence in the way that a general introduction can. Introduction to Philosophy as a Way of Life may ultimately lean more heavily in an ethical direction than many other general introductory courses, but its ability to step back and investigate other areas of philosophy offers a richer tapestry from which to pull than a dedicated ethics course. 


\subsection{The need for traditional philosophy in a general introduction}

A second concern one might raise is that by focusing on PWOL rather than SOPP, a general introductory course will, at some level, stop being about philosophical goals

like the search for truth and instead devolve into relativistic navel-gazing that hardly constitutes philosophy. If we are to offer a general introduction to philosophy, it must involve philosophy as it is traditionally construed.

Setting aside the view that introductory courses are not fruitful avenues for the investigation of the sorts of truths philosophers seek (Wright 20I9), such concerns are understandable, especially if one is unfamiliar with PWOL and its aims within the classroom. However, they represent either a misunderstanding about how to successfully engage in PWOL or a legitimate-but reasonable-disagreement about the relative focus of SOPP- and PWOL-based course content.

In the former case, it may be helpful to think about what is meant by Philosophy as a Way of Life. As Grimm has characterized the project, the focus of PWOL is twofold. First, one might ask what it is to have a way of life, which is a genuinely philosophical question worthy of consideration in a PWOL-based course. Second, one might ask what it means to have a philosophical way of life (Grimm 20I9). There are genuine disagreements about this, for example between Hadot's view of PWOL as a series of philosophically-oriented exercises (Hadot 1995) and Cooper's view of a life based on a commitment to reason (Cooper 20I2), but what is inescapable from any such view is that successful practice of philosophy is a prerequisite for engaging in PWOL. Thus, one cannot successfully practice PWOL either in the classroom or their own lives without the ability to engage in SOPP-based philosophy at some level because living a philosophical life requires the ability to engage in conceptual analysis, 
argument evaluation, and so on. Thus, any minimally satisfactory PWOL-based introduction will engage in SOPP at some level; to do otherwise would remove philosophy from philosophy as a way of life.

If one accepts the view that SOPP will necessarily be incorporated at some level in a PWOL-based introduction, the concern voiced above comes down to the degree to which SOPP is incorporated, rather than a concern about its total exclusion. To such concerns, I return to the idea of editorial judgment expressed when outlining PWOLbased general introductions earlier in this essay. Reasonable philosophers can disagree on how much SOPP is enough (or too much) based on their individual goals, the abilities of their students, and so forth, and it seems that other things being equal, we ought have no complaint with such assessments in our colleagues' own courses. But the reverse is also true; if a colleague views a PWOL-based general introduction as less desirable in its treatment of SOPP, there seems to be no convincing reason why that preference is indicative of a course that is insufficient, irresponsible, or unphilosophical.

\section{Conclusion}

Philosophy is a rich discipline that can critically inform our views of ourselves, the world around us, and how we ought to live. Unfortunately, few students get the opportunity to see this because the only course most students enroll in is a problematized general introduction that has little to say about questions of meaning and value. Philosophy as a Way of Life is an opportunity to refocus the general introductory course in a way that brings such questions front and center. Doing so has a number of benefits, both philosophical and pedagogical. Most notably in my view, a 
PWOL-based general introduction represents a forceful defense of the power of philosophy to contribute to one's good life by providing the opportunity to engage in investigations vital to students' own lives. This is in addition to pedagogical benefits like the enhanced ability to engage in high impact practices, situate skill development so that students are more likely to succeed, and engage in meaningful disciplinary practice.

Throughout the inaugural Philosophy as a Way of Life conference, the metaphor of tourists, travelers, and natives was frequently employed. Two key distinctions that separated the two groups were the time one spent engaged in a particular place or culture and one's willingness to step off the well-trod path to seek one's own experiences. Tourists, for example, often stay with the guide or visit only well-known locations over brief visits, while travelers linger longer and seek out their own adventures. With enough time and exposure, such travelers may even become natives or something like natives.

Traditional SOPP-based introductions function much more analogously to tour guides, shepherding students from an exhibit on epistemology here to the philosophy of mind wing of the museum there. PWOL-based courses, on the other hand, invite students to become philosophical travelers, immersing themselves in philosophical practice even as it leads them off the beaten path of more traditional introductory offerings. They may never become natives like us—indeed, they are unlikely to engage in such disciplinary travel again during their education-but like the traveler whose life is forever changed by their backpacking or study abroad or extended stay, Philosophy as a Way of Life can give students an experience whose contours can 
positively influence their lives and how they live them. In my view, at least, it is hard

to see how a general introduction could be more successful.

\section{Works Cited}

Abrantes, José Luís, Cláudia Seabra, and Luís Filipe Lages. 2007. "Pedagogical Affect, Student Interest, and Learning Performance.” Journal of Business Research 60 (9): 960-64.

Angle, Stephen. 20II. "PHIL 22I: Philosophy as a Way of Life (Syllabus)." Wesleyan University. https://wesfiles.wesleyan.edu/courses/syllabi/ıII9-sangle-oI3ı9532I.pdf.

Bergin, Susan, and Ronan Reilly. 20I9. The Influence of Motivation and Comfort-Level on Learning to Program.

Besong, Brian. 20I6. “Teaching the Debate.” Teaching Philosophy 39 (4): 40I-I2. https://doi.org/I0.5840/teachphil20I6II2256.

Brent, Doug. 2005. "Reinventing WAC (Again): The First-Year Seminar and Academic Literacy." College Composition and Communication 57 (2): 253.

Burkard, Anne. 20I7. "Everyone Just Has Their Own Opinion: Assessing Strategies for Reacting to Students' Skepticism about Philosophy." Teaching Philosophy 40 (3): 297-322. https://doi.org/I0.5840/teachphil20I7IOI773.

Cashmore, Sarah. 2015. "Changing Values in Teaching and Learning Philosophy: A Comparison of Historic and Current Education Approaches." Teaching Philosophy 38 (2): 297-322. https://doi.org/I0.5840/teachphil20I532634.

Cheraksova, Evgenia. 20I4. "Philosophy 235: Meaning of Life (Syllabus)." Suffolk University. http://meaningoflife.cherkasova.org/wpcontent/uploads/20I4/o5/Meaning-of-Life_Web-Syllabus_20I4.pdf.

Christy, Justin. 20I9. "Peer-Led Dialogue and Philosophy as a Way of Life." presented at the Inaugural Mellon Philosophy as a Way of Life Workshop, The University of Notre Dame, June I7.

Cooper, John M. (John Madison). 2012. Pursuits of Wisdom : Six Ways of Life in Ancient Philosophy from Socrates to Plotinus. Princeton, N.J.: Princeton, N.J. : Princeton University Press.

Donley, David, Steven Haug, and Thomas Rule. 20I8. "Introduction to Philosophy as a Way of Life (Syllabus).” University of California, Santa Cruz. https://summer.ucsc.edu/courses/course-syllabi/20I8/20I8-phil-II-donley.pdf.

"God and the Good Life." 20I9. The University of Notre Dame. https://godandgoodlife.nd.edu/.

Grimm, Stephen. 2019. "What Is Philosophy as a Way of Life? Why Philosophy as a Way of Life." presented at the Inaugural Mellon Philosophy as a Way of Life Workshop, The University of Notre Dame, June I7.

Hadot, Pierre. 1995. Philosophy as a Way of Life: Spiritual Exercises from Socrates to Foucault. Oxford: Oxford.

Holme, Thomas A., Jessica J. Reed, Jeffrey R. Raker, and Kristen L. Murphy. 20I8. "The ACS Exams Institute Undergraduate Chemistry Anchoring Concepts Content 
Map IV: Physical Chemistry." Journal of Chemical Education 95 (2): 238-4I. https://doi.org/IO.IO2I/acs.jchemed.7boo53I.

Holme, Thomas, Cynthia Luxford, and Kristen Murphy. 2015. "Updating the General Chemistry Anchoring Concepts Content Map." Journal of Chemical Education 92 (6): III5-I6. https://doi.org/IO.IO2I/ed5007I2k.

Kenny, Shirley Strum, Bruce Alberts, Wayne Booth, Milton Glaser, Charles Glassick, Stanley Ikenberry, Kathleen Hall Jameson, et al. 1998. "Reinventing Undergraduate Education: A Blueprint for America's Research Universities.” BoyerComisiononEducatingUndergraduatesintheResearch University.

Kuh, George. 2008. High-Impact Educational Practices: What They Are, Who Has Access to Them, and Why They Matter. Washington, D.C.: AAC\&U.

Land, Ray, Glynis Cousin, Jan Meyer, and Peter Davies. 2005. “Threshold Concepts and Troublesome Knowledge (3): Implications for Course Design and Evaluation." In Improving Student Learning Diversity and Inclusivity, edited by Chris Rust, 53-64. Oxford: Oxford Centre for Staff and Learning Development. Langer, Ellen. 1993. "A Mindful Education." Educational Psychology 28I (I): 43-50. https://doi.org/IO.I207/sI5326985ep280I_4. . 2000. "Mindful Learning." Current Directions in Psychological Science 9 (6): 22023.

Langer, Ellen, Michael Hatem, Jennifer Joss, and Marilyn Howell. 1989. "Conditional Teaching and Mindful Learning." Creativity Research Journal 2 (3): 129-50. https://doi.org/I0.IO80/I04004I89095343II.

Marek, Keith A., Jeffery R. Raker, Thomas A. Holme, and Kristen L. Murphy. 2018. "The ACS Exams Institute Undergraduate Chemistry Anchoring Concepts Content Map III: Inorganic Chemistry." Journal of Chemical Education 95 (2): 23337. https://doi.org/IO.IO2I/acs.jchemed.7boo498.

Meyer, Jan, and Ray Land. 2005. "Threshold Concepts and Troublesome Knowledge (2): Epistemological Considerations and a Framework for Teaching and Learning." Higher Education 49:373-88. https://doi.org/I0.IO07/sIO734-004-6779-5. Momeyer, Richard. 1995. "Teaching Ethics to Student Relativists." Teaching Philosophy I8 (4): 305-II.

Pintrich, Paul R, and Elisabeth V De Groot. 1990. "Motivational and Self-Regulated Learning Components of Classroom Academic Performance." Journal of Educational Psychology 82 (I): 33.

Raker, Jeffrey, Thomas Holme, and Kristen Murphy. 2013. "The ACS Exams Institute Undergraduate Chemistry Anchoring Concepts Content Map II: Organic Chemistry." Journal of Chemical Education 90 (II): I443-45. https://doi.org/IO.IO2I/ed400I75w.

Stokes, Patrick. 2012. "Philosophy Has Consequences! Developing Metacognition and Active Learning in the Ethics Classroom." Teaching Philosophy 35 (2): 143-69.

Turner, Dale. 2013. "How to Teach: Critical Thinking." Teaching Philosophy 36 (4):3994I6. https://doi.org/I0.5840/teachphil20I3IOI5.

Walker, Matthew. 20I8. "Philosophy as a Way of Life (Syllabus)." Yale NUS. file:///Users/jake/Downloads/Philosophy_as_a_Way_of_Life_Yale-NUS_Col.pdf.

Wright, Jake. 20I9. "The Truth, but Not yet: Avoiding Naïve Skepticism via Explicit Communication of Metadisciplinary Aims." Teaching in Higher Education 24 (3): 36I-77. https://doi.org/I0.I080/I35625I7.20I8.I544552. 
Yuretich, Richard F., Samia A. Khan, R. Mark Leckie, and John J. Clement. $200 I$. "Active-Learning Methods To Improve Student Performance and Scientific Interest in a Large Introductory Oceanography Course." Journal of Geoscience Education 49 (2): III-I9. https://doi.org/I0.5408/I089-9995-49.2.III.

Zerr, Ryan J., and Elizabeth Bjerke. 2016. "Using Multiple Sources of Data to Gauge Outcome Differences between Academic-Themed and Transition-Themed First-Year Seminars." Journal of College Student Retention: Research, Theory \& Practice I8 (I): 68-82. https://doi.org/IO.II77/I52IO25II5579673. 